\title{
Leadership and Human Resource Development Role in the time of Crisis Management
}

\author{
Sarika Sharma \\ Research Scholar of Dr.APJ Abdul Kalam \\ Technical University, Uttar Pradesh, Lucknow \\ Assistant Professor, Integrated Academy of \\ Management and Technology, Ghaziabad \\ sarika.malhotra17@yahoo.co.in
}

\author{
Dr Shivani Agarwal* \\ Assistant Professor, KIET School of Management, \\ KIET Group of Institutions, Delhi-NCR, \\ Ghaziabad, India \\ jindal.shivani24@gmail.com
}

\begin{abstract}
The pandemic has created a gap between the people and the resources. In this situation, a leader is the only mediating force who can fill the gap between the employees and the organizational objectives. The objective of this paper is to examine the role of a leader and study the changing role of human resource development of an organization during a crisis. The study has been done through the study of three parameters concerning crisis management Leadership, Organizational Development, and Crisis Management. The methodology adopted for this paper through review of the literature. This paper is conceptual type paper. The research questions directing this work are 1 . What are the leadership attributes required during and post-times of crisis? 2. And what roles do human resource development practitioners imagine supporting their organizations during and post-times of crisis? The paper showcases the certain qualities of a leader which are required to handle the crisis effectively.
\end{abstract}

Index Terms-Leadership, Human Resource Development, Crisis Management, Covid-19.

\section{INTRODUCTION}

$\mathrm{R}$ ECENTLY the whole world faced the COVID-19 pandemic which has changed the very fiber of the modern workplace. It hit an enormous reset button on everything. Everything we were aware of in the workplace has changed forever. More than anything, we have all learned the importance of leadership during such uncertain times. It was leadership attributes that kept many companies coping during the pandemic, and it will be leadership that will help companies recover and thrive in a post-COVID-19 world. Certain qualities of leaders will help employees, associates, businesses, and even industries, come together around them and spark revitalization. The role of leader is not only required during the phase of Covid-19 but also has a positive impact after the post-Covid-19. The amount and speed of breakdown in different activities that have followed are unlike anything experienced in our lifetime [1]. In this paper, from the Human Resource Development perspective, how competent and efficient leaders can bring change at each stage of crises and help to lessen the effect of negative force, fear, and unambiguity not only in organizations but on individuals as well.

Crises can be defined as a situation that brings imbalance in our routine activity to a large extent and requires a quick and appropriate response to minimize the consequences. The researchers and practitioners have a different outlook to define it as a specific, unexpected, and non- routine event or series of events that create imbalance. There seems to be a

*__ Corresponding author direct relationship between leaders' viewpoints and crisis management. One's viewpoint related to any crisis is based upon how they perceive the situation and organize the information, and this becomes reality, and then the actions will be directed by this perception [14] explained the importance of perception to the crisis in the following definition: Crises are the joint products of unusual events and shared perceptions that something is seriously wrong. As one of the characteristics of perception is that any

Different individuals perceive $\&$ act differently towards the crisis based on their different values, norms, beliefs, and the capacity to handle the crisis.

According to [8] certain elements play a vital role in a crisis system. These elements include the external as well as the internal factors such as technology, organizational structure, human factors, organizational culture, and to some extent top management strategy \& mindset. Each of these elements can be a causal or consequential factor; a crisis event can pose a threat to the organization's core values modifying the existing culture into something different. The only element which can minimize \& control the effect and control the situation effectively is the effective leadership trait of the human being. Leader with his qualities of motivating and coordination can easily help others to cope up with unpredictable situations. Effective leadership especially plays the utmost role in handling critical situations. To make a prediction related to the outcome a leader requires understanding the culture of the organization and considering it seriously. However, not all leaders are equally capable dealing with crises.

Crises are unpredictable for the reason that they always occur without prior intimation or information. It requires prompt decision-making as it results in quick breaking. There are chances that a single crisis can generate many others elsewhere. It depends upon the organization's strategy to deal with.

\section{Specific Qualities of Leaders Required During Crisis}

The corona virus disease-19 (COVID-19) pandemic has globally created an exceptional humanitarian crisis. This unpredictable, uncertain $\&$ difficult time requires prompt decisions from a limited reliable source of information. To handle the situation effectively, the leaders have to learn how to manage with all these unknown elements, and need to develop new learning which helps to develop various creative and innovative problem-solving strategies to keep their en- 
terprise operational and stakeholder's safe. In this paper, certain characteristics and practices have been mentioned that effective leaders must represent during a time of crisis and discussed them in the context of the existing COVID-19 pandemic.

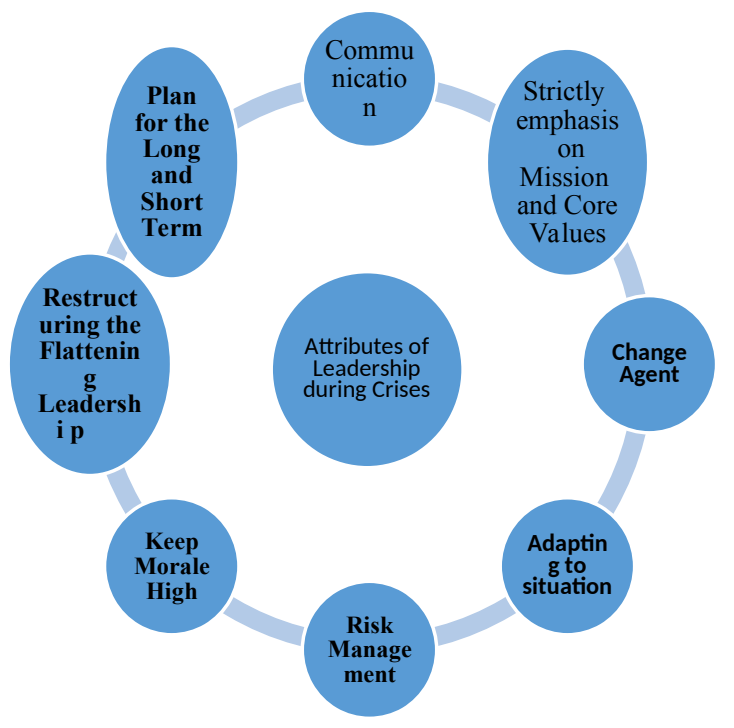

Source: Author's own work

\section{A. Communication}

Communication is a medium of expressing our thoughts, ideas, feelings, experiences among others. But the pandemic Covid-19 has brought a great impact on this communication process. Before the pandemic the situations were very different, like the employees meeting physically, making discussions, brainstorming and being able to understand the other's thought process in their working environment. But due to the restriction which pandemic has brought such as Work from Home, maintain social distancing, Lock down break the channel of communication among the employees, as well as with their leaders \& superiors. Lack of physical communication has given rise to ambiguity and in truthfulness which are the producers of anxiety among the people and workforce. It is perquisite for a leader to communicate clearly and make his organization or region aware about the reality and motivate by presenting a clear perspective of what is happening and how to deal with it. The essential of Communication is that it needs to be clear and reliable.

\section{B. Strictly emphasis on Mission and Core Values}

An unpredictable crisis is worked as both a challenge and as an opportunity too. It also provides a prospect time to any organization to review their core values. Instability and pandemic situations creates the environment which allows any organization to put their organizations' mission and core values for testing and it also provides an opportunity for effective leaders to reemphasize these values. Reviewing and restructuring of these values and of mission helps to stimulate and create a positive environment for others. It is also a sign of efficient leaders to identify and appreciate the effort of those who took initiative, showed voluntary participation and came across to give their best at the time of pandemic.
A successful leadership team encourages "outside the box" thinking to affect tragic events.

\section{Restructuring the Flattening Leadership Structure}

The need of the leaders in the organisation gets rapidly changed and unpredictable during crises. During a pandemic situation the senior leaders in the organizational hierarchies have a normal tendency to emphasize control, and take away the responsibility of leadership from their direct employee's suggestions, their ideas, and their needs which creates a sense of togetherness. The first step towards understanding and gaining knowledge is Humility, and the world needs humble leaders more than ever. This attitude assists the leader to create a bond with others and reflects that they genuinely care about their welfare. It is also seen that in the situation of crisis, it is easy to blame others. Criticize and focus on problem areas. The leaders who are focused in their approach try to choose the path by mutual discussion so that a solution can be found. He very well understands the crisis situation not to count the mistakes but to show the attitude of respect, trust, support, empathy towards their employees. Therefore, leaders need to get in touch with their humble side and continue to be great leaders.

\section{Plan for the Long and Short Term}

A good leader possesses the skills to understand the long term and short term goals of the organisation. They are efficient to apply scarce resources to meet the real time needs by maintaining attention on Long-term visionary goals. They are clear about the requirements of the situation and do not hesitate to make unique choices like, providing options to work from home, maintaining social distance, use of e-portals for hiring, conducting virtual meetings instead of physical one.

The organizations required different attributes of leader's post-COVID-19, because the change that has been brought on seems to be permanent, and only leaders with the abovementioned qualities will be able make an accurate difference.

\section{E. Change Agent}

Unpredictable pandemic has brought a lot of changes not only in the lives of individuals but also in the workplace. Employees are now working virtually and following the practice of work from home and also with the new teams that were never familiar with each other earlier. This new change has brought the need for a change agent in management style. There is a lot of a change in attitude and mindset of the employees in the organization. Employees are handling new and different tasks and more responsibilities individually. It's all about co-operation and working together. And as a leader, one is expected to manage employees and prepare employees to adapt to these new changes. They have to act to lead the way in the change. They are liable to create a sense of teamwork in the new hybrid teams, so they can also adapt to the new changes and continue to improve.

\section{F. Adapting to Situation}

Quick adaptation to prevailing situations is immediately required by the strong leaders. The COVID- 19 pandemic 
has exposed a number of the flaws in the system. It was exceptional. Nothing like this had ever been seen before or dealt with. But good leaders will quickly observe and adapt to the situation. Successful leaders will plan rules and regulations to protect not only people's health, but also related to their jobs and finances. Industry leaders will look at ways to create safe \& healthy working conditions and protect the jobs of the employees to provide them job security. WFH, Virtual \& digital implementation is one example of the quick adaptation to the situation.

\section{G. Keep Morale High}

The burden of dealing with the crisis is more than the crises itself and it brings people down. And here comes the role of leader to pick them up. Leader play a crucial role from taking decisions and making changes that encourage employees, to even directly communicating with each employee and assuring them of improvement in the situation. So a true leader will do whatever it takes to keep the morale high of his stakeholder. Certainly, this doesn't mean they have to hide the truth, it means they have put forward the optimistic attitude and help employee's to understand and act accordingly.

\section{H. Risk Management}

Leaders will be expected to be ready for better risk management as the financial and health risks have increased tenfold post Covid- 19. The COVID-19 pandemic uncovered the obvious gaps in current business and economic systems and all were caught unrehearsed. Leaders need to put in a lot of observation with time and effort into preparedness to lessen risk factors. One great action of readiness is WFH. The lockdown due to Covid-19 risk threatened business operations, but the WFH model ensured continued operations without employees losing jobs and moving to their workplace. It also supported businesses by saving money during the tough time. Similarly, leaders should be keen observers to quickly spot risk factors and come up with possibilities that protect the business, the employees, and customers.

\section{After the Effect of Crisis on Employees}

There is a lot of unpredictable situations which have no control in the pandemic situation for the organizations. Due to which the organizations have to work under a lot of ambiguity and stress that leads to the significant challenge for corporate functional leaders The central challenges during crisis management have been addressed as unrealistic and unclear information, new situations, uncertainty and shifting of goals, and ill- structured situations' as per the [6]. The value of human resources can't be measurable like capital or financial markets, yet the scholars of Human Resource states that Human Resource is one of the most important assets of an organization that will contribute highly in the growth of the organization [17]. [9] Stated that during uncertain times, retaining high skills and getting high productivity is a game of thoughtful planning. One must retain the highly skilled employees as retaining them also helps to retain their knowledge and skills [15]. Due to the unstable situation a number of organizations try to reduce the expense for the organization by minimizing the number of employees in the and also expects the greater amount of flexibility from the remaining employees from remaining employees [9].

\section{Need of Employees as an Individuals at the Time} OF CRISES

The successful leaders will help the organization and its employees to understand the complexity of the situation, align it with the organizational strategy, find out new ways to handle the situation, will focus on how to deal with complexity, and make the employees acceptable for the new way of working. Beside this efficient leaders will also support emotionally and psychologically to boost up the morale of the employees. The main task of the leaders in the situation of crises would be to review the situation, define the strategy required to recover the business, and to create a model for crisis management. In the coming sections, we will discuss HRD actions \& their importance of guiding support, psychological empowerment, recognition of work, positive reinforcement and, meaningful message from the leaders during these exceptional times of crisis, the COVID-19 pandemic.

\section{A. Support and Assistance from HRD}

The worth of the human resource of any organization is not measurable in capital. It is the function of HRD to emphasize the importance of the well-being of all human capital of any organization. They have to give extra effort to manage their physical, emotional, \& psychological well-being. As they are the most valuable assets of the organisation, it is the responsibility of HRD to understand the current mental condition of the employees and make strategies that will foster their performance and help them to cope up with the unseen danger during the crises. Leader has to create a link with his employees. He has to create an environment where the employees can freely share their concern with the leader and the leader effectively listens and understands their problems. Providing suitable suggestions and empowering the psychological and emotional condition of his employees at the time of crises is also a major responsibility of the leader. Leader has to keep himself updated about the current situation and also keep informed about his employees' situation creates job insecurity which will impact the emotional condition of the employees and that reflects in their day- to-day functioning. The leader can provide the exposure which can engage the employees which help to boost their motivation. The leader should create a flexible environment so that the employees can easily accept the new working environment. It totally depends upon the out of the box thinking, presence of mind to handle the novel situation and also to make the proper strategy for coping up with the changing situation [13].

\section{B. Appreciation \& Positive Motivation of work}

As crises create the environment of instability, appreciation, and acknowledgement of employee's efforts for their functions work as a positive reinforcement for them in the existing crisis Covid-19. [2] After his interaction with various industrialists concluded various needed skills for effective leadership. First, efficient leaders need to have a capability to deal positively with the stress, insecurity, anxiety the employees are carrying with them due to the uncertain 
crisis. Foresightness is the quality that helps the leaders to closely observe the situation and predict the challenges which might be overcome for the business in future.

\section{Technology enabler}

Technology plays a very important role in handling the pandemic existing situation of Covid-19. Leadership includes power for the expansion of integrating technology in the organization as per [10] and the updated technology helps the members to facilitate their activities [16]. As [12] mentions, leaders have to develop the skills of making the balance with adaptability and learning the new system, that will lead to high efficiency. One of the important trait of leadership is Adaptability which is arisen because of the uncertainty and the ambiguity due to the technological advancement and the economic growth [12].It's because of the flexible feature of technology that can help in reducing the stress and insecurity of employees as well as of leaders during Covid-19.It is the role of HRD to train and update their leaders with the use of new technology so that they can handle the crises effectively and promptly. Technology has helped almost every area of operations by allowing the people to work from home, virtual meetings, e-learning. As a result HRD practices a new way of learning which includes the different mode like e-learning, distance learning, selflearning, and online learning which have turned out to be in practice by all globally [4].As per the demand of the pandemic HRD professionals should train their leaders so that the leaders can support their employee to find out to their requirement and needs by the use of technology and try to meet those in an cost effective manner which will lead to the growth of organisation.

\section{Emotional stability and employee well-being}

The impact of crises can be seen in the emotional disturbance in any individual to some extent. It is again the role of the leader to understand the emotional and personal problems of all employees and guide them to handle them properly. The support is not only required during the crises but it is also post crises. [5] In their research they have presented their views on how the organisation must promote the practice to provide a space for employees so that they can express their grievance openly. HRD should assist to develop the leaders with emotional intelligence and emotional quotients. Both of these are the important traits of leadership [7].[16] states the importance of emotional-social intelligence model in providing assistance in the development of leadership and also aiming on the development of leader's overall personality, their intrapersonal \& interpersonal skills, interpersonal skills, their adaptability to the situation as well as skills to handle stress. HRD should develop a plan and training programmes for the leaders to develop interpersonal skills, emotional quotient, stress management techniques, and change management. The leaders have to fill the gap which has come across due to the absence of physical presence of employees at the workplace. They have to develop a plan with the HRD department to reach out to the employees virtually on a regular basis. This kind of virtual meeting with leaders helps the employees to develop the sense of security, and also provide psychological and emotional sup- port to meet better performance results. Work from home is also a big challenge for the employees and that requires the proper communication and clear directions from the leader.

\section{IMPLICATION}

As we discussed numerous qualities of the leaders which are required to be used effectively during the time of Pandemic, among those Clear communication comes first in the list. Another is organizational resilience. Resilience is the process of developing capability which allows the organisation to move to a new and better position after the crises. It is only possible through the efforts of the effective leader who can lead the organisation with innovative ideas and favorable strategies to absorb adverse situations effectively due to pandemic. All crises don't require the same style of leadership; resilience also acknowledges that there is no one best approach to be used in every pandemic. Distributing leadership has the power to create highly motivated teams which leads to an improved decision making process, and simultaneously increases the stakeholders' assurance to the organization and its survival [3].

\section{Conclusion \& Findings \& Limitations}

The study reveals the Importance of leadership during and post Covid 19 with the role of human resource development. The current study tries to show the more effective role of HRD in developing their leaders which further impact on the employees of the organisation in the situation of pandemic. In this regard we suggest HRD practitioners and research scholars need to critically observe the HRD involvements that can be functional during the pandemic time which brings a lot of instability and indecisiveness.

\section{REFERENCES:}

[1] Gopinath, G. (2020). The great lockdown: Worst economic downturn since the great depression. IMF blog, 14, 2020.

[2] McGuinness, J. 2020. "4 COVID-19 Leadership Lessons.” Chief Executive, May 12

[3] Kohlls, A. 2020. "How One Company Is Taking Care of Employees during COVID-19." Forbes, April 6

[4] Li, J., R. Ghosh, and S. Nachmias. 2020. "In a Time of COVID-19 Pandemic, Stay Healthy, Connected, Productive, and Learning: Words from the Editorial Team of HRDI." Human Resource Development

[5] Rocco, T. S., and B. Shuck. 2019. "Death and Dying: Grief, Compassion and Workplace Responses." New Horizons in Adult Education \& Human Resource Development 32 (1): 1-4

[6] Głodziński, E., \& Marciniak, S. (2016). Organisational innovations in crisis management of project-based enterprises. Economics and Business, 28(1), 26-32.

[7] Farina, F., and F. M. Nafukho. 2016. "Emotional Intelligence Research within Human Resource Development Scholarship.” European Journal of Training and Development 40 (2): 90-110.

[8] Naudé, M. 2012. "Global Economic crisis: Employee Responses and Practical Implications for Organizations.” Organization Development Journal 30 (4): 9-24.

[9] Kopp, D. M., I. Nikolovska, K. P. Desiderio, J. T. Guterman. 2011. “'Relax, I Remember the Recession in the Early 1980s': Organizational Storytelling as a Crisis Management Tool." Human Resource Development Quarterly 22(3):373-385

[10] Lewis, D. 2010. "The Principal as Technology Integration Leader. Graduate School of Computer Science and Information Sciences.”PhD diss., Nova Southern University.

[11] Colville, I. D., and A. J. Murphy. 2006. "Leadership as the Enabler of Strategizing and Organizing.” Long Range Planning 39 (6): 663-677 
[12] Schreiber, C., and K. Carley. 2006. "Leadership Style as an Enabler of Organizational Complex Functioning." Emergence: Complexity and Organization 8 (4): $61-76$

[13] Eraut, M. 2006. "Schon Shock: A Case for Refraining Reflection-inaction." Teachers and Teaching Theory and Practice 1 (1): 9-22.

[14] Ramlall, S. 2004. "A Review of Employee Motivation Theories and Their Implications for Employee Retention within Organizations." Journal of American Academy of Business 5 (1/2): 52-63

[15] Adkins, C. L., Werbel, J. D., J. L. Farh. 2001. A Field Study of Job Insecurity During a Financial Erisis." Group \& Organization Management 26: 463-483

[16] Stokowski, W. J. 1992. "The Duality of Technology: Rethinking the Concept of Technology in Organizations." Organization Science 3 (3): $398-427$.
[17] Jacobs, R. L. 1990. "Human Resource Development as an Interdisciplinary Body of Knowledge.” Human Resource Development Quarterly 1 (1): 65-71.

[18] Agarwal, S., Garg, P., \& Rastogi, R. (2011). Impact of quality of work life on employee trust. International Journal of Management Research, 54.

[19] Mewafarosh, R., \& Agarwal, S. Influence of demographics variables on students subjective well-being. Journal of Public Affairs, e2749. (Scopus, ABDC Listed) (1479-1854).

[20] Shivani Agarwal and Rekha Mewafarosh (2021). "Linkage of Social Media Engagement with FOMO and Subjective Well Being", Journal of Content, Community \& Communication, Vol. 13, pp 46-57.

[21] Agarwal, S. (2020). Trust as a missing link between quality of work life and subjective well-being. Ingeniería Solidaria, 16(1), pp (1-21). 